\title{
Effect and mechanism of miR-146a on malignant biological behaviors of lung adenocarcinoma cell line
}

\author{
FANG YUAN ${ }^{1,2}$, SUYUN ZHANG $^{3}$, WENYING XIE $^{3}$, SHENG YANG $^{3}$, TINGYAN LIN $^{1}$ and XIANGQI CHEN ${ }^{1}$ \\ ${ }^{1}$ Department of Respiratory Medicine, Fujian Medical University Union Hospital, Fuzhou, Fujian 350001; \\ ${ }^{2}$ Department of Respiratory, The First Hospital of Jiujiang City, Jiujiang, Jiangxi 332000; ${ }^{3}$ Department of Oncology, \\ Fujian Medical University Union Hospital, Fuzhou, Fujian 350001, P.R. China
}

Received November 18, 2018; Accepted June 28, 2019

DOI: $10.3892 / 01.2020 .11474$

\begin{abstract}
The aim of the present study was to assess the expression of microRNA-146a (miR-146a) in human lung adenocarcinoma cells, its effect on cellular behaviors, and the underlying molecular mechanisms. Reverse transcription-quantitative PCR (RT-qPCR) was used to measure miR-146a expression in the human normal lung epithelial cell line, BEAS-2B, and human lung adenocarcinoma cell lines, A549, PC-9 and H1299, to determine whether miR-146a acts as an oncogene or anti-oncogene. miR-146a mimics were transfected into target cells to observe the proliferation, apoptosis, invasion and migration of human lung adenocarcinoma cells. The target genes of miR-146a were predicted using bioinformatics analysis, and binding sites were validated by dual-luciferase reporter assay. Target gene expression at the mRNA and protein levels was measured by RT-qPCR and western blot analysis, respectively. The expression levels of miR-146a in human lung adenocarcinoma cell lines were lower than its expression in BEAS-2B $(\mathrm{P}<0.01)$. A549 cell line is a EGFR wild-type lung adenocarcinoma cell line, which is also the most widely studied in NSCLC, and therefore this was chosen as the target cell line for further investigation. Overexpression of miR-146a in A549 cells can inhibit cell proliferation $(\mathrm{P}<0.05)$, promote apoptosis $(\mathrm{P}<0.05)$, and reduce the cells' migratory ability $(\mathrm{P}<0.01)$. Bioinformatics prediction indicated that interleukin-1 receptor-associated kinase 1 (IRAK1) and TNF receptor associated factor 6 (TRAF6) are the target genes of miR-146a. Dual-luciferase reporter assay showed that miR-146a could specifically bind to 3'-untranslated regions of IRAK1 and TRAF6. The protein and mRNA levels of IRAK1 and TRAF6
\end{abstract}

Correspondence to: Professor Tingyan Lin or Professor Xiangqi Chen, Department of Respiratory Medicine, Fujian Medical University Union Hospital, 29 Xinquan Road, Fuzhou, Fujian 350001, P.R. China

E-mail:drchxq@163.com

E-mail:drlcxhhx@126.com

Key words: microRNA-146a, lung adenocarcinoma cell, malignant biological behavior, mechanistic research were significantly downregulated after miR-146a overexpression in A549 cells $(\mathrm{P}<0.01)$. The results of this study demonstrated that the expression of miR-146a in human lung adenocarcinoma cells was significantly lower than in normal lung epithelial cells, indicating that miR-146a acts as an anti-oncogene. miR-146a suppresses the proliferation and migration of human lung adenocarcinoma cells by downregulating the expression of IRAK1 and TRAF6.

\section{Introduction}

Previous research has shown that lung cancer is the leading cause of cancer-associated mortality in China, but also worldwide, with a morbidity rate and mortality rate of 11.6 and $18.4 \%$, respectively (1-3). Due to the high degree of malignancy and rapid development of lung cancer, lack of clinical symptoms in the early stage and the lack of an effective screening program, $>70 \%$ of patients are diagnosed with advanced stage disease (stage III/IV) (4). It has been previously reported that $\sim 60 \%$ of patients diagnosed with non-small-cell lung cancer (NSCLC) die within 1 year, because they are unable to undergo any surgical resection, and due to the occurrence of local recurrence and distant metastasis during the treatment process (5). In recent years, the main treatments for advanced NSCLC have been chemotherapy, molecular-targeted therapy and developing immunotherapy (6-8). Although molecular targeted therapies have resulted important changes in the treatment of NSCLC, especially for adenocarcinoma, the odds of patients with lung cancer surviving for at least 5 years after diagnosis remain $<15 \%$ (9). The pathogenesis behind lung cancer has not been fully elucidated, and research has shown that factors such as polygenes may be involved. Research has found that microRNAs (miRNAs/miR) have an important role in the occurrence and progression of tumors via the regulation of target genes (10). Therefore, miRNAs may be key for tumor intervention therapy (11). miRNA-146a is located in the LOC285628 gene on human chromosome 5. The LOC285628 gene is composed of two exons separated by $\sim 16 \mathrm{~kb}$. The sequence encoding miR-146a is located in the second exon. In 2008, Jazdzewski et al (12) proposed that the pre-miR-146a gene polymorphism may serve a role in thyroid papillary carcinoma. miR-146a was subsequently examined in gastric cancer, esophageal cancer, liver cancer, breast cancer, ovarian 
cancer and other tumors. In 2011, Vinci et al (13), studied the genetic polymorphisms and expression of miRNAs in NSCLC, and later found that miR-146a may increase the risk of NSCLC. In the past five years, the number of studies on the effects of miR-146a on NSCLC has increased greatly. Only $20 \%(5 / 20)$ of the manuscripts regarding miR-146a in NSCLC could be retrieved before 2014, and the remaining manuscripts were retrieved from 2015 to 2019.

Research has indicated that miR-146a has great impact on proliferation, apoptosis, invasion and metastasis of lung cancer (14). Although the specific mechanism, to the best of our knowledge, has not been fully explored, miR-146a may be important for developing new and effective therapeutic targets, becoming one of the hotspots in cancer research. In the present study, reverse transcription-quantitative PCR (RT-qPCR) was used to detect the miR-146a level in three lung adenocarcinoma cell lines. Furthermore, the effects of miR-146a on the malignant biology of lung adenocarcinoma cells were examined. Finally, the molecular mechanism of the effects of miR-146a was explored.

\section{Materials and methods}

Cell lines and cell culture. Human lung epithelial cells, BEAS-2B, were obtained from China Center for Type Culture Collection and human lung adenocarcinoma cells, A549, H1299 and PC-9, were obtained from the Pharmacology Department of Fujian Medical University (Fujian, China). All cells were cultured in RPMI-1640 medium with 10\% FBS (both HyClone; GE Healthcare Life Sciences) and $100 \mathrm{U} / \mathrm{ml}$ penicillin and $100 \mu \mathrm{g} / \mathrm{ml}$ streptomycin (Gibco; Thermo Fisher Scientific, Inc.). All cells were incubated at $37^{\circ} \mathrm{C}$ with $5 \% \mathrm{CO}_{2}$.

RT-qPCR and the expression levels of miR-146a in human lung adenocarcinoma cells. The expression of miR-146a in human lung adenocarcinoma cells, A549, H1299 and PC-9, and human lung epithelial cells, BEAS-2B, were measured using RT-qPCR. Total RNA was extracted from cells using TRIzol (Invitrogen; Thermo Fisher Scientific, Inc.). The purity and concentration of RNA were assessed using NanoDrop 2000 (Thermo Fisher Scientific, Inc.). cDNA was synthesized according to the instructions included with the miRNA reverse transcription kit (Invitrogen; Thermo Fisher Scientific, Inc.) and performed using the following conditions: Incubation at $42^{\circ} \mathrm{C}$ for $60 \mathrm{~min}, 95^{\circ} \mathrm{C}$ for $5 \mathrm{~min}$, and held at $4^{\circ} \mathrm{C}$, until subsequent experimentation. qPCR reaction system was prepared with the SYBR Green qPCR Supermix (Promega Corporation), according to the manufacturer's protocols. qPCR reaction conditions were as follows: $95^{\circ} \mathrm{C}$ for $3 \mathrm{~min}$; followed by 40 cycles of $95^{\circ} \mathrm{C}$ for $15 \mathrm{sec}, 60^{\circ} \mathrm{C}$ for $30 \mathrm{sec}$, and $68^{\circ} \mathrm{C}$ for $1 \mathrm{~min}$. U6 served as an internal normalized reference. The primers of miR-146a and U6 are shown in Table I. Quantification of relative expression was performed using the $2^{-\Delta \Delta \mathrm{Cq}}$ method (15), where $\Delta \Delta \mathrm{Cq}=[\mathrm{Cq}($ miRNA) $-\mathrm{Cq}(\mathrm{U} 6)]$ experimental group $-[\mathrm{Cq}(\mathrm{miRNA})-\mathrm{Cq}(\mathrm{U} 6)]_{\text {control group }}$.

Experimental group and transfection. The experimental cells were divided into 3 groups: Mimics group, transfected with Cy3-miR-146a mimics (5'-UGAGAACUGAAUUCC AUGGGUU-3'; Shanghai GenePharma Co., Ltd.) as the experimental group; negative control (NC; 5'-UUCUCCGAA CGUGUCACGUTT-3') group, transfected with miR-146a analogue nonsense sequences (Shanghai GenePharma Co., Ltd.) as the negative control group; and mock group, treated with Lipofectamine ${ }^{\circledR} 2000$ only (Invitrogen; Thermo Fisher Scientific, Inc.). The day before transfection, A549 cells were seeded on a 24-well-plate and allowed to incubate overnight, after which their confluency was $30-50 \%$. The cells were transfected using Lipofectamine ${ }^{\circledR} 2000$ (Invitrogen; Thermo Fisher Scientific, Inc.), according to the manufacturer's protocols.

Transfection efficiency of miR-146a. After $6 \mathrm{~h}$ of transfection, the approximate transfection efficiency was observed and calculated using fluorescence microscopy in which five random fields were observed at x200 magnification. The cells were continued to be cultured after the medium was replaced. Total RNA was extracted from the three groups at $48 \mathrm{~h}$ after transfection. The expression of miR-146a in the three groups was measured using RT-qPCR. U6 was used as an internal reference. Primers are shown in Table I.

Cell proliferation assay. Cell proliferation was assessed by Cell Counting Kit-8 (CCK-8) assay (Beyotime Institute of Biotechnology). Briefly, the three groups of A549 cells were incubated in 96-well plates at a density of $2.5 \times 10^{3}$ cells/well. The cells were cultured for $12,24,36,48,60$ and 72 h. A total of $10 \mu \mathrm{l}$ CCK-8 reagent was subsequently added to each well, and cells were returned to incubation for 1-2 h. Light absorbance was measured at a wavelength of $450 \mathrm{~nm}$ using a microplate reader. The resulting value was used to represent cell proliferation activity.

Apoptosis assay. A549 cells were inoculated into 6-well plates with the density of $1 \times 10^{6}$ cells/well. At $48 \mathrm{~h}$ after transfection, the Annexin V-FITC and propidium iodine (PI) reagents (Nanjing KeyGen Biotech Co., Ltd.) were added, according to the protocols of the Annexin V-FITC apoptosis kit. The rate of apoptosis was determined by flow cytometry after 15 min of staining.

Transwell and Matrigel assays. Transwell chambers were placed into a 24-well plate and Matrigel was diluted at 1:16 using RPMI-1640. $60 \mu 1$ diluted Matrigel was added to the upper chamber and incubated at $37^{\circ} \mathrm{C}$ for $3 \mathrm{~h}$. A549 cells of the three groups were digested and resuspended at $24 \mathrm{~h}$ after transfection. The cells were diluted with $200 \mu 1$ serum-free medium $\left(1 \times 10^{5} / \mathrm{ml}\right)$ and added into the upper chamber of Transwell chamber, and $600 \mu \mathrm{l}$ RPMI-1640 culture medium containing with $20 \%$ FBS was added to the lower chamber. After $24 \mathrm{~h}$ of cell culture, the cells were removed from the upper surface of the polycarbonate membrane with a wet cotton swab. The filter membrane was fixed with $4 \%$ polyformaldehyde for $10 \mathrm{~min}$ at room temperature, stained with $0.1 \%$ crystal violet for $30 \mathrm{~min}$ at room temperature, and rinsed with double distilled water for $5 \mathrm{~min}$. Subsequently, five fields of view were randomly selected using light microscopy (Olympus Corporation) at low magnification, the number of invading cells was counted, and the mean average was calculated.

Wound-healing assay. The three groups of A549 cells were seeded into 6 -well plates at a density of $1 \times 10^{6}$ cells/well. 
Cells were starved with serum-free medium for $12 \mathrm{~h}$. A $10 \mu \mathrm{l}$ pipette tip was used create a scratch across the center of each well. Images were obtained at 0 and $48 \mathrm{~h}$ of culture to assess wound-healing using light microscopy (x100 magnification; Olympus Corporation).

Target gene prediction and dual-luciferase assay. Target genes of miR-146a were predicted using the bioinformatics software TargetScan (http://www.targetscan.org/vert_72/) and miRDB (http://mirdb.org/). Dual-luciferase assay was used to validate the association between miR-146a and the predicted targets. The wild-type 3'-untranslated region (UTR; IRAK1-WT and TRAF6-WT) and mutant 3'-UTR (IRAK1-MUT and TRAF6-MUT) of target genes were inserted into the pGL3 promoter vector (Shanghai GenePharma Co., Ltd.) the vector $(0.4 \mathrm{mg})$ and miR-146a mimic or NC (10 pmol) were transfected into A549 cells using Lipofectamine ${ }^{\circledR} 2000$ (Invitrogen; Thermo Fisher Scientific, Inc.). The cells were diluted to $1 \times 10^{5} / \mathrm{ml}$ and cultured in a 24-well plate. Firefly and Renilla luciferase activities were quantified using the dual-luciferase reporter assay system (Promega Corporation) according to the manufacturer's instructions $48 \mathrm{~h}$ following co-transfections. The automatic microplate reader (Molecular Devices, LLC) was used in luciferase assays detection.

mRNA expression of target genes as determined using $R T-q P C R$. The extraction of total RNA, synthesis of cDNA, and fluorescence quantitative PCR were performed in accordance with the steps described above. The relative mRNA expression of the target genes was calculated using GAPDH as an internal reference. The primers required for the experiment are presented in Table I.

Protein expression of target genes as detected by western blot analysis. The three groups of cells were lysed with RIPA lysis buffer on ice at $48 \mathrm{~h}$ after transfection. The supernatant was retained after high-speed centrifugation $(12,000 \times \mathrm{g}$ at $4^{\circ} \mathrm{C}$ ) and the protein concentrations were measured using a BCA kit (Beyotime Institute of Biotechnology). Equal amounts of protein $(15 \mu \mathrm{g})$ were separated by SDS-PAGE on $10 \%$ gels (Beijing Solarbio Science \& Technology Co., Ltd.), and transferred to PVDF membranes. The PVDF membranes were blocked with 5\% skim milk at room temperature for $2 \mathrm{~h}$. They were then incubated with primary antibodies against interleukin-1 receptor-associated kinase 1 (IRAK1; dilution, 1:1,000; cat. no. ab180747; Abcam), TNF receptor associated factor 6 (TRAF6; dilution, 1:1,000; cat. no. ab33915; Abcam) and GAPDH (dilution, 1:10,000; cat. no. ab181602; Abcam) at $4{ }^{\circ} \mathrm{C}$ overnight. The membranes were then incubated with horseradish peroxidase-conjugated goat anti-rabbit secondary antibody (dilution, 1:5,000; cat. no. BB-2202; BestBio Company; http://bestbio.bioon.com.cn/) at room temperature for $2 \mathrm{~h}$. Proteins were visualized by chemiluminescence using an ECL kit (Beyotime Institute of Biotechnology), according to the manufacturer's protocols. The expression of proteins was quantified using densitometry analysis (ChemiDoc ${ }^{\mathrm{TM}} \mathrm{XRS}+$ gel imaging system) and analysed using image lab $^{\text {TM }}$ software (version 3.0; both Bio-Rad Laboratories, Inc.).
Table I. Primer sequences used for amplification.

\begin{tabular}{ll}
\hline Primer & \multicolumn{1}{c}{ Sequence (5'-3') } \\
\hline RT & GTCGTATCCAGTGCAGGGTCCGAGGTATTC \\
& GCACTGGATACGACAACCCA \\
miR-146a & Forward CGGCGGTGAGAACTGAATTCCA \\
miR-146a & Reverse GTGCAGGGTCCGAGGT \\
U6 & Forward GCTTCGGCAGCACATATACTAAAAT \\
U6 & Reverse CGCTTCACGAATTTGCGTGTCAT \\
IRAK1 & Forward GTGGACACGGACACCTTCAG \\
IRAK1 & Reverse CTCCTCAGCCTCCTCTTCCA \\
TRAF6 & Forward GGAACCCTAGCCCATCGTCA \\
TRAF6 & Reverse GGAACCCTAGCCCATCGTCA \\
GAPDH & Forward AGAAGGCTGGGGCTCATTTG \\
GAPDH & Reverse AGGGGCCATCCACAGTCTTC
\end{tabular}

RT represents the sequence of the miR-146a primer used for reverse transcription. IRAK1, interleukin-1 receptor-associated kinase 1; TRAF6, TNF receptor associated factor 6; miR-146a, microRNA-146a.

Table II. Relative expression level of miR-146a in the four cell lines.

\begin{tabular}{lc}
\hline Group & miR-146a (mean \pm standard deviation) \\
\hline A549 & $0.325 \pm 0.069^{\mathrm{a}}$ \\
PC-9 & $0.193 \pm 0.100^{\mathrm{a}}$ \\
H1299 & $0.090 \pm 0.020^{\mathrm{a}}$ \\
BEAS-2B & 1.000 \\
\hline
\end{tabular}

${ }^{\mathrm{a}} \mathrm{P}<0.01 . \mathrm{miR}$, microRNA.

Statistical analysis. Data were analyzed by SPSS 24.0 (IBM Corp.). Values are expressed as the mean \pm standard deviation of three independent experiments. All P-values were calculated using unpaired Student's t-test or one-way analysis of variance with Tukey's post hoc test. $\mathrm{P}<0.05$ was considered to indicate a statistically significant difference.

\section{Results}

miR-146a is downregulated in human lung adenocarcinoma cell lines. The expression of miR-146a in three human lung cancer cell lines A549, H1299 and PC-9, and normal human lung epithelial cells, BEAS-2B, was detected by RT-qPCR. The expression of miR-146a in BEAS-2B and the relative expression in other cell lines is presented in Table II. The results showed that the expression of miR-146a in three human lung cancer cell lines was significantly lower than in human normal lung epithelial cells $(\mathrm{P}<0.01$; Fig. 1$)$.

Cell transfection. Human lung adenocarcinoma cell line A549 was transfected with Cy3-miR-146a mimics and the transfected cells were observed using a fluorescence microscope after $6 \mathrm{~h}$ (Fig. 2A). A total of $65 \pm 3.5$ cells were counted in 
light microscopy images, while $62 \pm 4.7$ cells were counted in fluorescence microscopy images. The transfection efficiency in A549 cells reached $95.4 \%$.

At $48 \mathrm{~h}$ after transfection, the transfection efficiency of miR-146a mimics in A549 cells was assessed by RT-qPCR. The miR-146a expression level in the mock group was set to 1 , and the relative expression levels of miR-146a in the NC group and the mimics group were $0.76 \pm 0.24$ and $11,097.93 \pm 1,926.50$, respectively (Fig. 2B). The results showed that after the transfection of miR-146a mimics, the expression of miR-146a was significantly higher in the mimic group than in the $\mathrm{NC}$ and mock groups $(\mathrm{P}<0.01$; Fig. $2 \mathrm{~B})$. This indicated that miR-146a was successfully overexpressed in human lung adenocarcinoma cell line A549.

Overexpression of miR-146a inhibits the proliferation and induces cell apoptosis of A549 cells. To determine the role of miR-146a in lung adenocarcinoma cell lines, miR-146a was overexpressed and the effect of miR-146a on the proliferation of A459 cells was assessed by CCK-8 assay. The OD values of A549 cells were measured at 12, 24, 36, 48, 60 and $72 \mathrm{~h}$ after transfection (Table III). There were no significant differences in proliferation among the three groups at $12 \mathrm{~h}$ ( $P>0.05$ ); however, at 24, 36, 48, 60 and $72 \mathrm{~h}$, the $\mathrm{OD}$ values of the mimics group were significantly lower than those of the nc and mock groups $(\mathrm{P}<0.05$ and $\mathrm{P}<0.01$; Fig. $3 \mathrm{~A})$. The CCK-8 assay indicated that overexpression of miR-146a reduces the proliferation of A549 cells. In order to determine whether miR-146a can promote apoptosis of A549 cells, a flow cytometry assay was performed at $48 \mathrm{~h}$ after A549 cells were transfected. The results showed the rates of apoptosis in the mimics, nc and mock groups to be $19.600 \pm 0.990$, $9.800 \pm 1.131$ and $13.701 \pm 0.707 \%$, respectively $(\mathrm{P}<0.05$; Fig. 3B and C). These results indicated that overexpression of miR-146a inhibited the proliferation and promoted apoptosis of A549 cells.

Overexpression of miR-146a inhibits the migration of A549 cells. Taking into account the low levels of miR-146a expression in human lung adenocarcinoma cells, and the fact that miR-146a inhibits proliferation and promotes apoptosis of A549 cells, this study subsequently examined whether miR-146a may affect cell migration. To address this, Transwell and wound-healing assays were conducted $48 \mathrm{~h}$ after cells were transfected. The results of the Transwell assay showed that the number of cells passing through the membrane in the mimics group $(212 \pm 6.000)$ was significantly lower than in the nc group $(588 \pm 60.357)$ and mock group (572 \pm 25.166 ; $\mathrm{P}<0.01$; Fig. 4A). In the wound-healing assay, images of the scratches in the three groups at 0 and $48 \mathrm{~h}$ after transfection, and the sizes of the healing areas were calculated accordingly. Five randomly selected fields of view along each wound were marked, and the wound area was measured, and the average wound-healing area was determined as the wound area of this wound and calculated as follows: The wound-healing area=wound area of $0 \mathrm{~h}$-wound area of $48 \mathrm{~h}$. Wound-healing area was first compared to the wound area at $0 \mathrm{~h}$, and subsequently compared to the $\mathrm{NC}$ and mock groups. The area of cell monolayer healing in the mimics group was significantly smaller $(26.32 \pm 3.11 \%)$ than that in the NC group $(63.42 \pm 0.17 \%)$ and in the mock group $(63.17 \pm 3.73 \%$; $\mathrm{P}<0.05$; Fig. 4B). Results

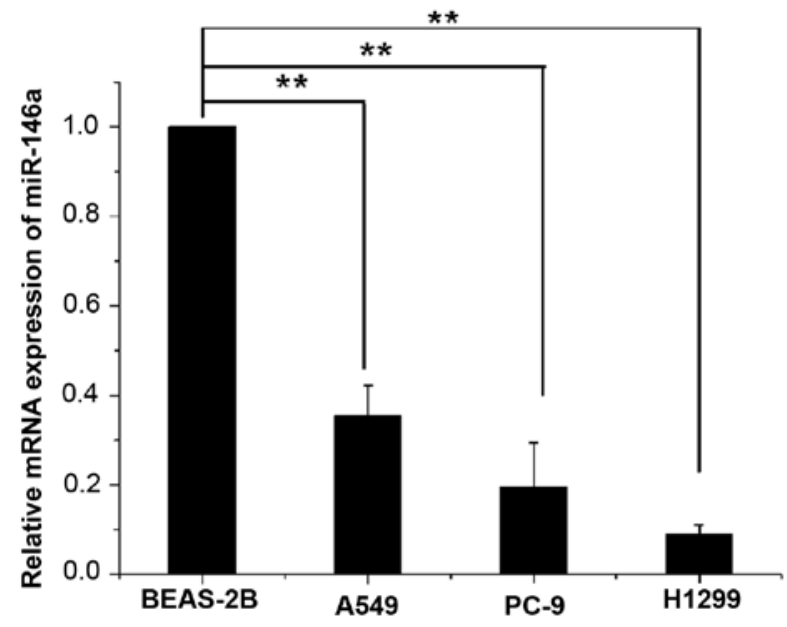

Figure 1. Relative mRNA expression of miR-146a in the four cell lines. Expression of miR-146a in three lung adenocarcinoma cell lines (A549, H1299, and PC9) and a human normal bronchial epithelial cell line (BEAS-2B). Expression of miR-146a was significantly lower in all three lung adenocarcinoma cell lines than in the normal epithelial cell line. ${ }^{* *} \mathrm{P}<0.01$. miR-146a, microRNA-146a.
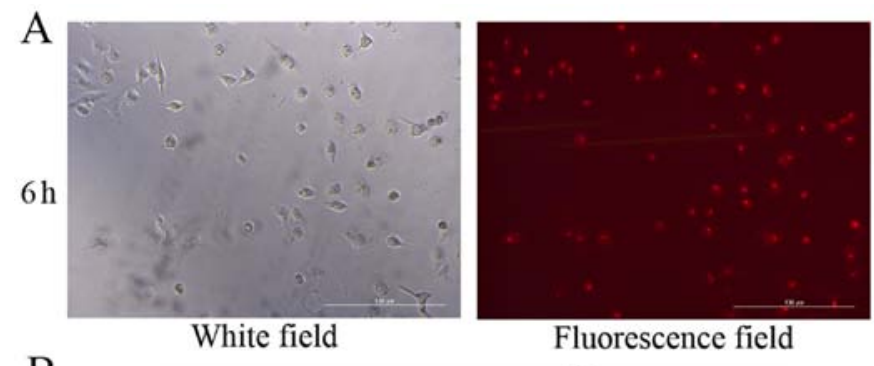

$\mathrm{B}$

Fluorescence field

**

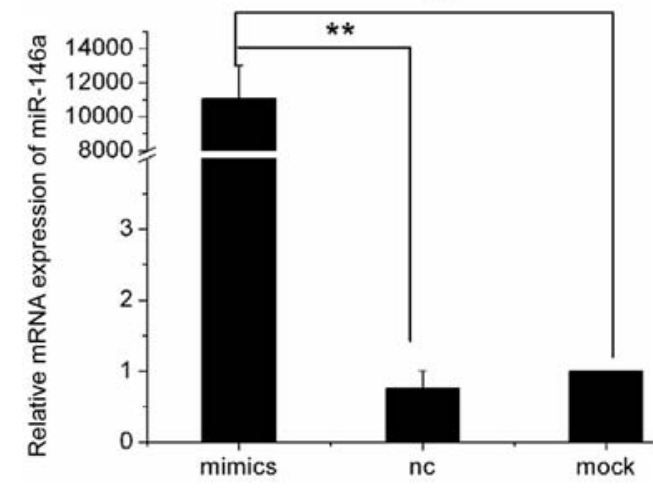

Figure 2. Transfection efficiency of miR-146a mimics in A549 cells (A) A549 cells were photographed under a microscope $6 \mathrm{~h}$ after transfection. The overall transfection efficiency was $95.4 \%$. Scale bar, $100 \mu \mathrm{m}$ (x100 magnification). (B) At $48 \mathrm{~h}$ after transfection, the expression of miR-146a in A549 cells was measured and the expression of miR-146a was significantly higher in the mimic group than in the $\mathrm{NC}$ and mock groups. ${ }^{* *} \mathrm{P}<0.01 \mathrm{vs.} \mathrm{NC}$ and mock group. miR-146a, microRNA-146a; NC, negative control.

showed that overexpression of miR-146a inhibited migration in vitro.

Detection of miR-146a targeted genes. The target genes of miR-146a were predicted using bioinformatics tools using the databases TargetScan and miRDB. After reviewing previous publications (16-18), IRAKI and TRAF6 were selected as target genes in lung cancer and were used for the 
Table III. Overexpression of miR-146a promotes proliferation of A549 cells.

Time point (h)

\begin{tabular}{lcccccl}
\cline { 2 - 6 } Group & \multicolumn{1}{c}{24} & \multicolumn{1}{c}{36} & \multicolumn{1}{c}{48} & \multicolumn{1}{c}{60} \\
\hline miR-mimics & $0.539 \pm 0.046$ & $0.696 \pm 0.010^{\mathrm{a}, \mathrm{b}}$ & $0.827 \pm 0.027^{\mathrm{c}, \mathrm{d}}$ & $0.899 \pm 0.082^{\mathrm{a}, \mathrm{b}}$ & $1.235 \pm 0.027^{\mathrm{a}, \mathrm{b}}$ & $1.458 \pm 0.048^{\mathrm{a}, \mathrm{b}}$ \\
miR-NC & $0.582 \pm 0.014$ & $0.863 \pm 0.070$ & $1.070 \pm 0.085$ & $1.197 \pm 0.094$ & $1.588 \pm 0.008$ & $1.749 \pm 0.114$ \\
Mock & $0.575 \pm 0.027$ & $0.880 \pm 0.049$ & $1.000 \pm 0.035$ & $1.176 \pm 0.086$ & $1.549 \pm 0.126$ & $1.797 \pm 0.040$
\end{tabular}

${ }^{\mathrm{a}} \mathrm{P}<0.01$ vs. NC; ${ }^{\text {}} \mathrm{P}<0.01$ vs. mock; ${ }^{\mathrm{c}} \mathrm{P}<0.05$ vs. NC; ${ }^{\mathrm{d}} \mathrm{P}<0.05$ vs. mock. Data are presented as the mean \pm standard deviation.

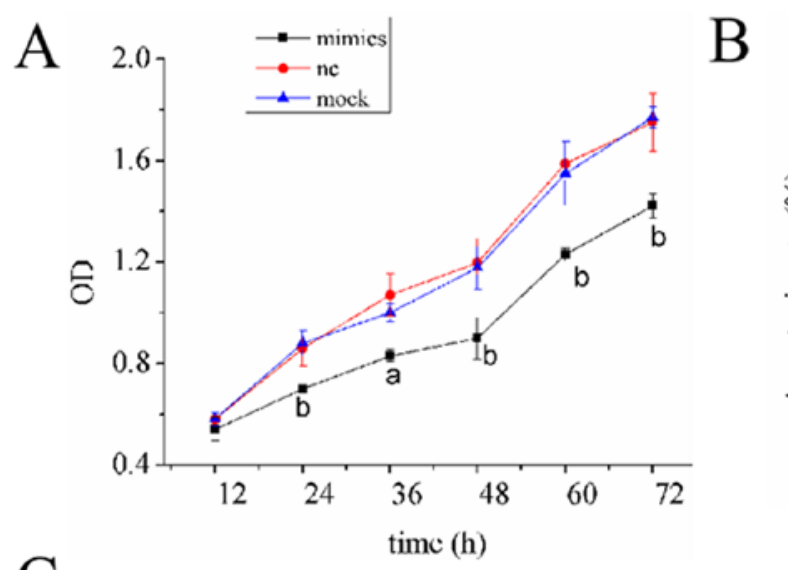

mimics

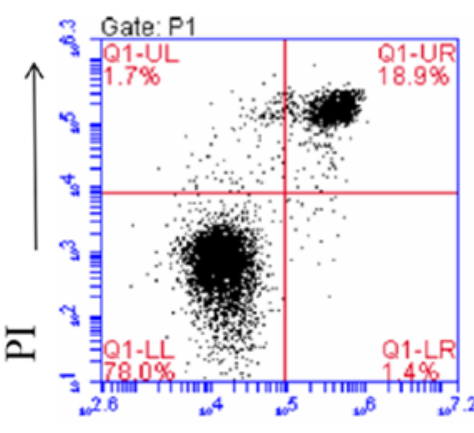

FITC

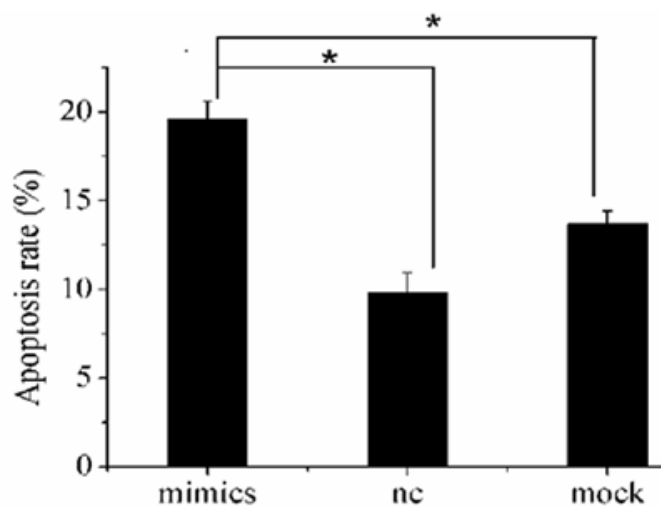

nc
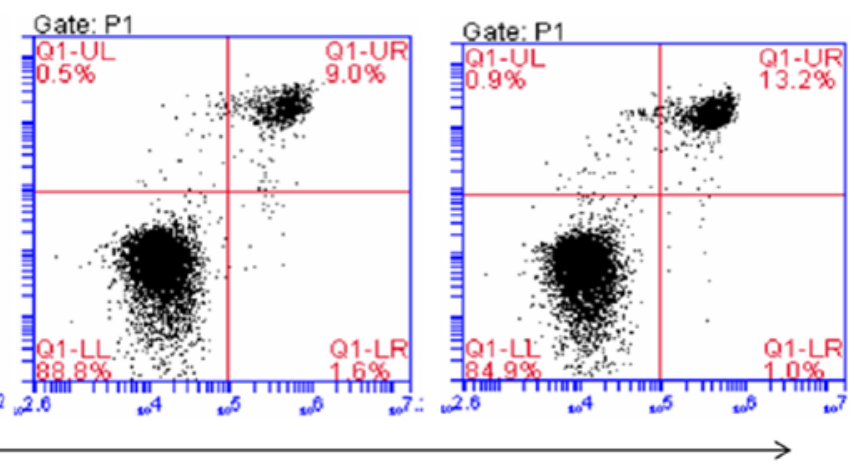

Figure 3. Effects of miR-146a overexpression on proliferation and apoptosis in A549 cells. (A) The OD values of A549 cells were measured at 12, 24, 36, 48, 60 and $72 \mathrm{~h}$ after transfection. The values of the mimics group were smaller than the nc group and the mock group at 24, 36, 48, 60 and 72 h. (B and C) At $48 \mathrm{~h}$ after transfection, miR-146a overexpression was found to promote apoptosis of A549 cells. " $\mathrm{P}<0.05$ vs. mock and NC group. miR-146a, microRNA-146a; $\mathrm{NC}$, negative control; OD, optical density; PI, propidium iodine.

dual-luciferase assay. Bioinformatics predicted the presence of miR-146a-binding sites in the 3'-UTRs of IRAKI and TRAF6 (Fig. 5). The wild-type and mutant 3'-UTRs of IRAKI and TRAF6 were used for the construction of recombinant luciferase expression vectors IRAK1-WT, IRAK1-MUT, TRAF6-WT, and TRAF6-MUT, and the vectors were co-transfected with miR-146a mimics or miR-146a nc to measure luciferase activity. The ratios of firefly luciferase activity to Renilla luciferase activity in the co-transfected groups, IRAK1-WT + miR-146a mimics group and TRAF6-WT + miR-146a mimics group, were significantly lower than in the $\mathrm{WT}+\mathrm{NC}$ and the MUT + miR-146a mimics and $\mathrm{NC}$ groups $(\mathrm{P}<0.05$ and $\mathrm{P}<0.01$;
Fig. 6A and B). The results indicated that miR-146a could specifically bind to 3'-UTRs of IRAKI and TRAF6.

Overexpression of miR-146a inhibits IRAK1 and TRAF6 in A549 cells. To further examine the signaling pathway that miR-146a regulates, and prove that miR-146a can regulate IRAK1 and TRAF6, the mRNA and protein expression levels of these two genes were measured by RT-qPCR and western blot analysis. RT-qPCR assay showed that mRNA levels of both target genes in the experimental group transfected with miR-146a mimics were significantly lower than in the nc and mock groups $(\mathrm{P}<0.05$ and $\mathrm{P}<0.01$; Fig. $7 \mathrm{~A})$. In addition, the results of the western blot experiment also indicated that 
A

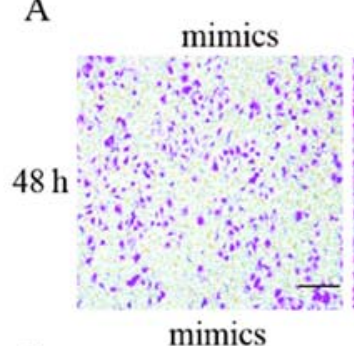

$\mathrm{C}$

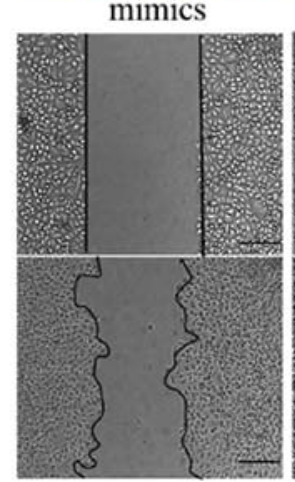

nc

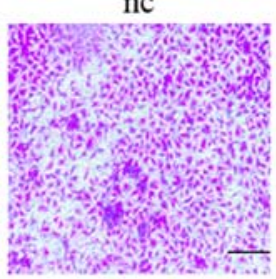

nc

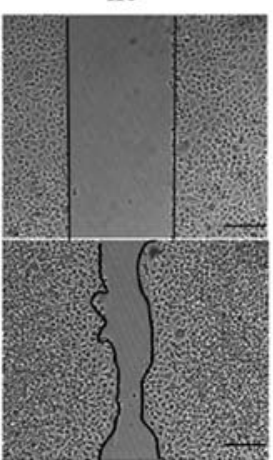

mock

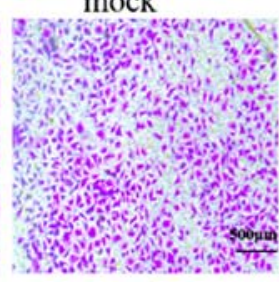

mock

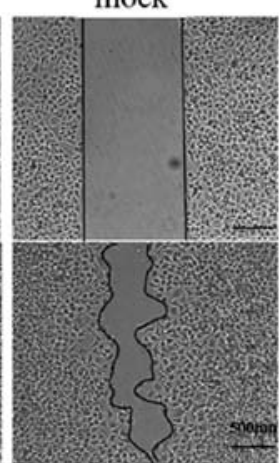

B

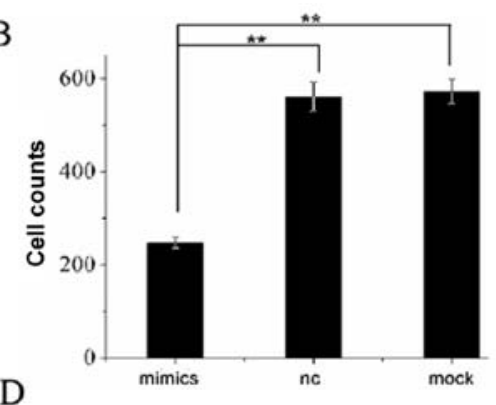

D

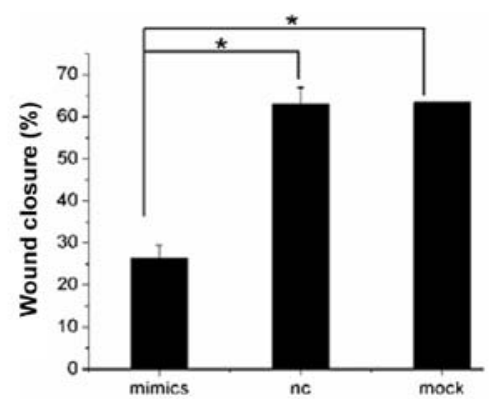

Figure 4. miR-146a overexpression inhibits migration of A549 cells. (A) Overexpression of miR-146a was found to inhibit the migratory ability of A549 cells in the Transwell experiment. (C and D) Images of wound-healing were taken at $0 \mathrm{~h}$ and $48 \mathrm{~h}$, and the area of healing represented the migration ability. The assay showed that miR-146a inhibited the migration ability of A549 cells Scale bar, $200 \mu \mathrm{m}$ (x100 magnification) ${ }^{* *} \mathrm{P}<0.01$ and ${ }^{*} \mathrm{P}<0.05$ vs. mock and NC group. miR-146a, microRNA-146a; NC, negative control.

\begin{tabular}{|c|c|}
\hline $\begin{array}{l}\text { Position 473-480 of TRAF6 3' UTR } \\
\text { Hsa-miR-146a-5p }\end{array}$ & $\begin{array}{l}5^{\prime} \text {...UGCUCUAGAAAGUUGAGUUCUCA... } \\
\qquad\|\|\|\| \| \\
3^{\prime} \quad \text { UUGGGUACCUUAAGUCAAGAGU }\end{array}$ \\
\hline $\begin{array}{l}\text { Position 538-545 of TRAF6 3' UTR } \\
\text { Hsa-miR-146a-5p }\end{array}$ & $\begin{array}{l}\text { 5'... UCCUUGGAAAACUUAAGUUCUCA... } \\
\|\|\|\| \mid\|\quad\|\|\|\|\| \\
\text { 3' UUGGGUACCUUAAG-_--UCAAGAGU }\end{array}$ \\
\hline $\begin{array}{l}\text { Position 1272-1279 of TRAF6 3' UTR } \\
\text { Hsa-miR-146a-5p }\end{array}$ & $\begin{array}{c}5^{\prime} \ldots \text { AAUAUCGUGGAAUCUAGUUCUCA... } \\
\qquad\||\|||||||||||| \mid \\
3^{\prime} \quad \text { UUGGGUACCUUAAGUCAAGAGU }\end{array}$ \\
\hline $\begin{array}{l}\text { Position 40-47 of IRAK1 3' UTR } \\
\text { Hsa-miR-146a-5p }\end{array}$ & $\begin{array}{l}\text { 5'...AAAUCCGGAAGUCAAAGUUCUCA... } \\
\text { || }|||||||||||| \mid \\
\text { 3' UUGGGUACCUUAAG----UCAAGAGU }\end{array}$ \\
\hline $\begin{array}{l}\text { Position 56-63 of IRAK1 3' UTR } \\
\text { Hsa-miR-146a-5p }\end{array}$ & $\begin{array}{c}\text { 5'...GUUCUCAUGGUCAGAAGUUCUCA ... } \\
\text { || }|||||||||||| \\
3 ' \quad \text { UUGGGUACCUUAAGUCAAGAGU }\end{array}$ \\
\hline
\end{tabular}

Figure 5. Binding sites of miR-146a with IRAK1 and TRAF6. IRAK1, interleukin-1 receptor-associated kinase 1; TRAF6, TNF receptor associated factor 6; UTR, untranslated region; miR-146a, microRNA-146a.

the protein levels of IRAKI and TRAF6 were inhibited after miR-146a overexpression in A549 cells $(\mathrm{P}<0.05$ and $\mathrm{P}<0.01$; Fig. 7B and C). This investigation of the underlying mechanism shows that miR-146a can regulate the expression of IRAKI and TRAF6, at the mRNA and protein level.

\section{Discussion}

With the development of modern gene technologies and the exploration of candidate genes and genomes, evidence has shown that lung cancer cells accumulate a large number of gene mutations during cancer development and progression, including inactivation of tumor suppressor genes and activation of oncogenes, which promote the growth or survival of tumor cells (19). miRNA molecules have been identified as a class of novel regulatory molecules that negatively regulate gene expression. These non-coding small RNAs are generally 18-25 nucleotides long, and they form gene regulation networks through complex interactions with their target genes, which are cell- and tissue-specific, and can regulate many physiological and pathological processes in humans (20). The main mechanism of miRNA regulation is to induce the degradation of target mRNA and inhibit its post-transcriptional translation by completely or partially complementing the 3'-UTR 
A

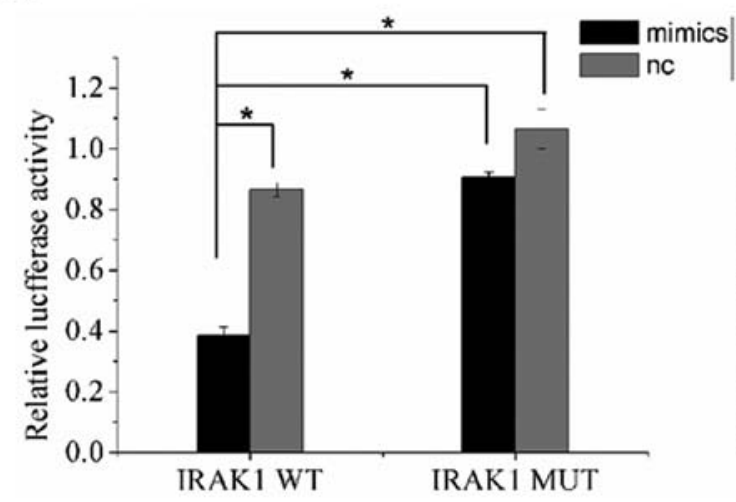

B

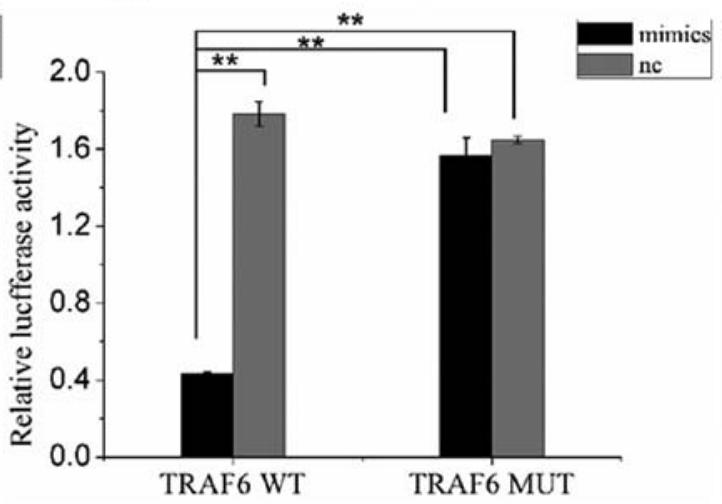

Figure 6. Detection of miR-146a targeted genes using a dual-luciferase reporter assay system. There was a profound decrease in the luciferase activity in A549 cells co-transfected with miR-146a mimics and (A) IRAK1-WT or (B) TRAF6-WT, ${ }^{*} \mathrm{P}<0.05$ and ${ }^{* *} \mathrm{P}<0.01$ vs. mock and NC group. miR-146a, microRNA-146a; NC, negative control; WT, wild-type; MUT, mutant.
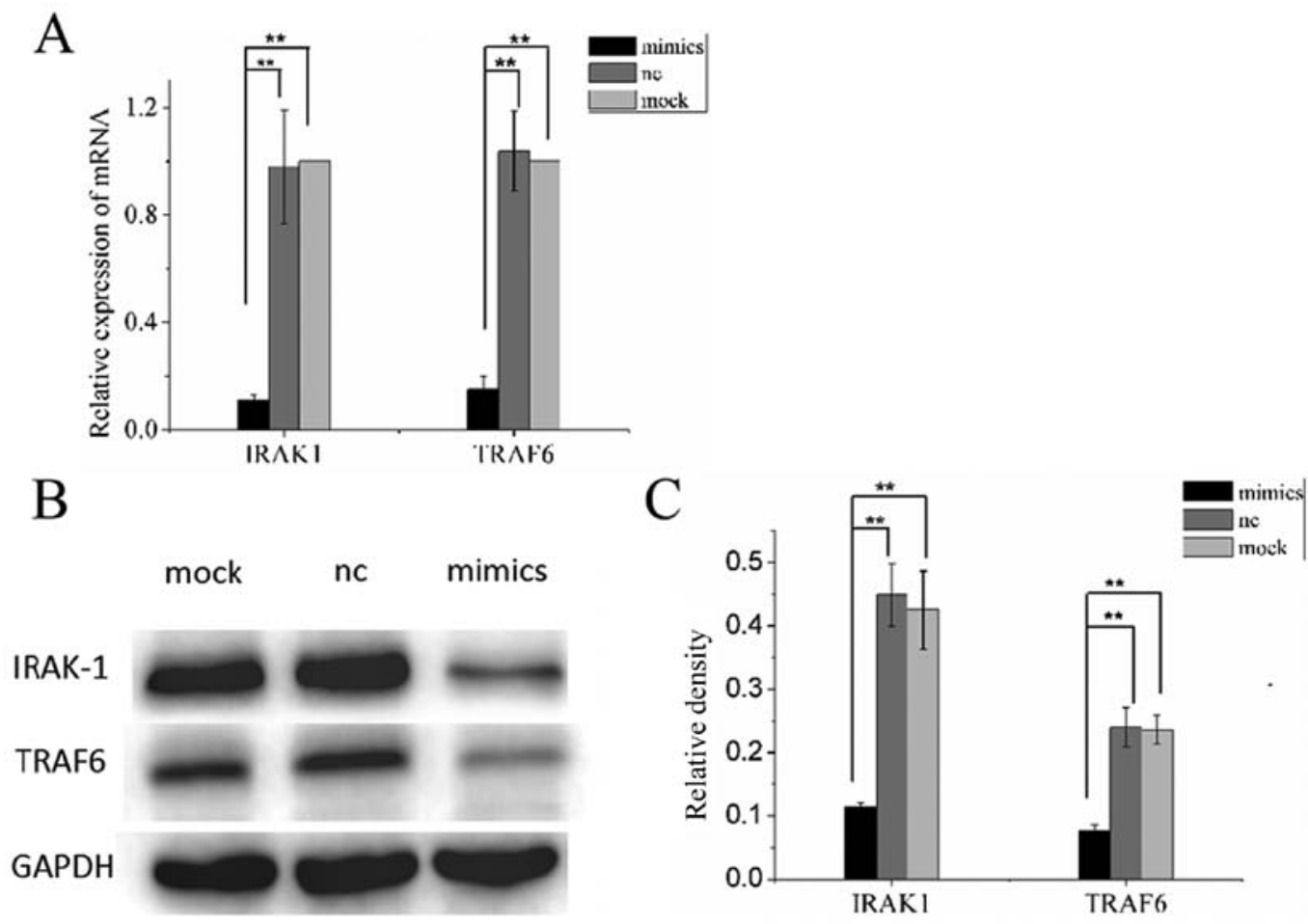

Figure 7. Overexpression of miR-146a and inhibition of IRAK1 and TRAF6 in A549 cells. (A) mRNA expression levels, and (B) western blot analysis and $(C)$ densitometry analysis of protein expression levels indicated that at $48 \mathrm{~h}$ after transfection, overexpression of miR-146a inhibited the mRNA and protein expression levels of IRAK1 and TRAF6. ${ }^{* *} \mathrm{P}<0.01$ vs. mock and NC group. miR-146a, microRNA-146a; NC, negative control; IRAK1, interleukin-1 receptor-associated kinase 1; TRAF6, TNF receptor associated factor 6.

of the target mRNA (21). A number of studies have reported abnormal expression of miRNA to be associated with the pathogenesis of various human tumors; miRNA has functions similar to those of proto-oncogenes or tumor suppressor genes, in addition to playing important roles in the development and progression of tumors $(22,23)$.

Lung cancer is the most common clinical primary malignant tumor, with $80-85 \%$ of cases being NSCLC, and lung adenocarcinoma is the main type of NSCLC (24). Due to the difficulty of early diagnosis of lung adenocarcinoma, the majority of cases are diagnosed at the advanced stage and are difficult to radically resect surgically. Therefore, chemotherapy and targeted therapy are the main treatments for NSCLC. However, unsatisfactory curative effect and poor prognosis are observed in a large number of patients (25). The identification and assessment of new therapeutic targets has become urgent in the diagnosis and treatment of lung adenocarcinoma. miR-146a plays important roles in the development and progression of many types of tumors, and it has been widely studied and reported in recent years. The expression of miR-146a is decreased significantly in breast $(26,27)$, liver $(28,29)$, prostate (30) and bladder cancer (31), and upregulation of miR-146a can inhibit the proliferation, invasion, and metastasis of these tumor cells and promote apoptosis (26-31); 
however, the expression of miR-146a is significantly higher in thyroid follicular carcinoma $(32,33)$ and oral carcinoma (34), and the downregulation of miR-146a expression can inhibit the malignant biological behaviors of tumor cells. In addition, the negative feedback mechanism associated with miR-146a is not applicable to all tumor cells (35). The underlying mechanism of miR-146a in different types of tumor cells requires further study.

In 2011, Vinci et al (13) measured the expression of several miRNAs in NSCLC and found the expression of miR-146a to be increased, therefore increasing the risk of NSCLC. In 2015, Wang et al (36) also observed the upregulation of miR-146a in NSCLC by RT-qPCR. However, in 2013, Chen et al (37) reported that the expression of miR-146a was reduced in NSCLC, which suggested that miR-146a may have a role as a tumor suppressor gene. Wang et al (38) showed similar results. These data indicated that, in lung cancer, the role of miR-146a and whether it acts as an oncogene or a tumor suppressor gene remains debatable.

In this study, the expression of miR-146a in BEAS-2B human normal lung epithelial cells and three human lung adenocarcinoma cell lines (H1299, A549, and PC-9) were measured using RT-qPCR. The results showed that the expression of miR-146a in human lung adenocarcinoma cell lines was significantly lower than that in human normal lung epithelial cells, indicating that miR-146a plays an important role as a tumor suppressor gene in NSCLC. The extensively used human lung adenocarcinoma cell line A549, which has high miR-146a expression was examined. Therefore, these cells were transfected with miR-146a using the liposome method to establish miR-146a-overexpressing A549 cells. The results showed that overexpression of miR-146a not only inhibited the proliferation of A549 cells, but also promoted apoptosis and inhibited the migratory ability of A549 cells, suggesting the role of miR-146a as a tumor suppressor gene in lung cancer.

One miRNA can target several mRNAs, and one target gene can be co-regulated by multiple miRNAs (39); the biological functions of miRNAs mainly depend on the roles of the downstream target genes. In 2010, Li et al (40) reported that, in pancreatic cancer, the inhibitory effect of miR-146 on the invasion of pancreatic cancer cells was associated with the downregulation of metastasis associated 1 family member 2 , IRAK1, epidermal growth factor receptor (EGFR), and NF- $\mathrm{B}$ signaling pathways by miR-146. In 2011, Garcia et al (41) reported that $\mathrm{miR}-146 \mathrm{a}$ could promote the proliferation and invasion of triple-negative breast cancer cells by downregulating BRCA1. In 2014, Forloni et al (42) reported that miR-146a could promote the development and progression of melanoma by activating the Notch signaling pathway. In 2013, Chen et al (37) indicated that upregulation of miR-146a significantly decreased the expression of EGFR in NSCLC cell lines. In 2014, Cornett and Lutz (43) found that miR-146a could target cyclooxygenase 2 in NSCLC. In 2016, Li et al (14) showed that miR-146a could inhibit the proliferation and cell cycle progression of NSCLC cells by targeting cyclin D1 and cyclin D2. In this study, the downstream target genes of miR-146a were predicted using the bioinformatics tools Target Scan, Pictar, and miRDB, which indicated that miR-146a may regulate IRAK1 and TRAF6 by binding to the 3'-UTR of IRAK1 and TRAF6. In 2013, Hung et al (34) reported that miR-146a enhanced the carcinogenicity of oral cancer by targeting IRAK1 and TRAF6 simultaneously. However, the role of IRAK1 and TRAF6 as miR-146a target genes in NSCLC, to the best of our knowledge, has not been reported.

In this study, the target genes were verified by the dual-luciferase reporter assay system, and the results showed the activity ratios of firefly luciferase to Renilla luciferase in A549 cells transfected with miR-146a-mimics + IRAK1-WT and miR-146a-mimics + TRAF6-WT to be significantly lower than those transfected with miR146a-nc+IRAK1-WT and miR146a-nc + TRAF6-WT. In the control groups, however, the activity ratios in A549 cells transfected with miR-146a-nc + IRAK1-MUT and miR146a-mimics + IRAK1-WT, and miR-146a-mimics + TRAF6-MUT and miR146a-nc + TRAF6-MUT, showed no significant difference. The above results confirmed that miR-146a could specifically bind to the 3'-UTR of IRAKI and TRAF6, therefore, blocking the transcription of the luciferase gene and decreasing the ratio of luciferase activity. However, when the 3'-UTR of IRAKI and TRAF6 were mutated, the binding sites of miR-146a were destroyed, and the transcription of the luciferase gene was not affected, so the ratio of luciferase activity did not differ significantly. This indicated that IRAKI and TRAF6 are the target genes directly regulated by miR-146a.

In this study, the effects of miR-146a on mRNA and protein levels were also verified by RT-qPCR and western blot analysis, respectively. The results indicated that, in the mimics group, the relative expressions of IRAK1 and TRAF6 mRNA and the relative gray values of proteins were lower and weaker than those in the nc and mock groups $(\mathrm{P}<0.05)$, which further confirmed that miR-146a can simultaneously target IRAK1 and TRAF6 activities and therefore act as a tumor suppressor. Additionally, in 2006, Taganov et al (44) reported that miR-146a could bind to IRAK1 and TRAF6, which encode the adaptor molecules between Toll-like receptors (TLRs) and NF- $\kappa \mathrm{B}$, inhibiting the expression of IRAK1 and TRAF6, therefore reducing the downstream $\mathrm{NF}-\kappa \mathrm{B}$ activity after TLR activation. Labbaye and Testa (45) confirmed the aforementioned results in 2012. In 2015, Park et al (46) and Yousefzadeh et al (47) also reported that miR-146a inhibits the activation of the NF- $\kappa$ B pathway by inhibiting the expression of IRAK1 and TRAF6, reducing the production of inflammatory cells and preventing the immune system from overreacting. Therefore, in lung cancer miR-146a may increase activation of the NF- $\kappa$ B signaling pathway by targeting IRAK1 and TRAF6. Further investigation on the specific mechanisms involved is required.

In conclusion, the expression of miR-146a in human lung adenocarcinoma cells decreased significantly, so it may play a role as a tumor suppressor gene. The upregulation of miR-146a significantly inhibited the proliferation, growth and metastasis of human lung adenocarcinoma cell line A549 and promoted apoptosis. miR-146a likely exerts its biological functions by targeting the activity of IRAKI and TRAF6 genes, therefore affecting the downstream signaling pathways. However, whether miR-146a also regulates other target genes to inhibit the activity of lung cancer cells requires further study. Further exploration and understanding of the mechanism by which miR-146a acts in lung adenocarcinoma may provide new effective targets for clinical molecular therapy for lung cancer. 


\section{Acknowledgements}

Not applicable.

\section{Funding}

This work is partially supported by the Medical Elite Cultivation Program of Fujian (grant no., 2013-ZQN-JC-14), The Fourth Round of Fujian Provincial Joint Tackling Project between Health and Education-Joint Research Fund of National Health and Family Planning Commission of China (grant no., WKJ2016-2-30), the Fujian Medical Innovation Project (grant no., 2014-CX-14) and the Science Technology Innovation Joint Project Foundation of Fujian Province (grant no. 2016Y9028).

\section{Availability of data and materials}

The datasets used and/or analyzed during the current study are available from the corresponding author on reasonable request.

\section{Authors' contributions}

$\mathrm{XC}$ and TL conceived the study, and analyzed and interpreted the data. FY performed the experiments, analyzed data and wrote the manuscript. SZ and WX performed the experiments and analyzed data. SY designed experiments, analyzed the data, polished the manuscript and guided the reply to the comments. All authors read and approved the final manuscript.

\section{Ethics approval and consent to participate}

Not applicable.

\section{Patient consent for publication}

Not applicable.

\section{Competing interests}

The authors declare that they have no competing interests.

\section{References}

1. Bray F, Ferlay J, Soerjomataram I, Siegel RL, Torre LA and Jemal A: Global cancer statistics 2018: GLOBOCAN estimates of incidence and mortality worldwide for 36 cancers in 185 countries. CA Cancer J Clin 68: 394-424, 2018.

2. Voltaggio L, Cimino-Mathews A, Bishop JA, Argani P, Cuda JD, Epstein JI, Hruban RH, Netto GJ, Stoler MH, Taube JM, et al Current concepts in the diagnosis and pathobiology of intraepithelial neoplasia: A review by organ system. CA Cancer J Clin 66: 408-436, 2016.

3. Chen W, Zheng R, Baade PD, Zhang S, Zeng H, Bray F, Jemal A, Yu XQ and He J: Cancer statistics in China, 2015. CA Cancer J Clin 66: 115-132, 2016.

4. Berghmans T, Pasleau F, Paesmans M, Bonduelle Y, Cadranel J, Cs Toth I, Garcia C, Giner V, Holbrechts S, Lafitte JJ, et al: Surrogate markers predicting overall survival for lung cancer: ELCWP recommendations. Eur Respir J 39: $9-28,2012$

5. Feber A, Xi L, Luketich JD, Pennathur A, Landreneau RJ, Wu M, Swanson SJ, Godfrey TE and Litle VR: MicroRNA expression profiles of esophageal cancer. $\mathrm{J}$ Thorac Cardiovasc Surg 135: 255-260, 2008
6. Cufer T and Knez L: Update on systemic therapy of advanced non-small-cell lung cancer. Expert Rev Anticancer Ther 14: 1189-1203, 2014.

7. Domingues D, Turner A, Silva MD, Marques DS, Mellidez JC, Wannesson L, Mountzios G and de Mello RA: Immunotherapy and lung cancer: Current developments and novel targeted therapies. Immunotherapy 6: 1221-1235, 2014.

8. Casaluce F, Sgambato A, Sacco PC, Palazzolo G, Maione P, Rossi A, Ciardiello F and Gridelli C: Emerging drugs targeting PD-1 and PD-L1: Reality or hope? Expert Opin Emerg Drugs 19: 557-569, 2014.

9. Li CM, Chu WY, Wong DL, Tsang HF, Tsui NB, Chan CM, Xue VW, Siu PM, Yung BY, Chan LW and Wong SC: Current and future molecular diagnostics in non-small-cell lung cancer. Expert Rev Mol Diagn 15: 1061-1074, 2015.

10. Slezak-Prochazka I, Durmus S, Kroesen BJ and van den Berg A: MicroRNAs, macrocontrol: Regulation of miRNA processing. RNA 16: 1087-1095, 2010.

11. Eder $\mathrm{M}$ and Scherr M: MicroRNA and lung cancer. N Engl J Med 352: 2446-2448, 2005.

12. Jazdzewski K, Murray EL, Franssila K, Jarzab B, Schoenberg DR and de la Chapelle A: Common SNP in pre-miR-146a decreases mature miR expression and predisposes to papillary thyroid carcinoma. Proc Natl Acad Sci USA 105: 7269-7274, 2008.

13. Vinci S, Gelmini S, Pratesi N, Conti S, Malentacchi F, Simi L, Pazzagli M and Orlando C: Genetic variants in miR-146a, miR-149, miR-196a2, miR-499 and their influence on relative expression in lung cancers. Clin Chem Lab Med 49: 2073-2080, 2011.

14. Li YL, Wang J, Zhang CY, Shen YQ, Wang HM, Ding L, Gu YC, Lou JT, Zhao XT, Ma ZL and Jin YX: miR-146a-5p inhibits cell proliferation and cell cycle progression in NSCLC cell lines by targeting CCND1 and CCND2. Oncotarget 7: 59287-59298, 2016.

15. Livak KJ and Schmittgen TD: Analysis of relative gene expression data using real-time quantitative PCR and the 2(-Delta Delta C(T)) method. Methods 25: 402-408, 2001.

16. Jiang W, Kong L, Ni Q, Lu Y,Ding W, Liu G, Pu L, Tang W and Kong L: miR-146a ameliorates liver ischemia/reperfusion injury by suppressing IRAK1 and TRAF6. PLoS One 9: e101530, 2014

17. Santra M, Zhang ZG, Yang J, Santra S, Chopp M and Morris DC: Thymosin $\beta 4$ up-regulation of microRNA-146a promotes oligodendrocyte differentiation and suppression of the Toll-like proinflammatory pathway. J Biol Chem 289: 19508-19518, 2014.

18. Selvamani SP, Mishra R and Singh SK: Chikungunya virus exploits miR-146a to regulate NF- $\kappa \mathrm{B}$ pathway in human synovial fibroblasts. PLoS One 9: e103624, 2014.

19. Zochbauer-Muller S, Gazdar AF and Minna JD: Molecular pathogenesis of lung cancer. Annu Rev Physiol 64: 681-708, 2002.

20. Makeyev EV and Maniatis T: Multilevel regulation of gene expression by microRNAs. Science 319: 1789-1790, 2008.

21. Van Den Berg A, Mols J and Han J: RISC-target interaction: Cleavage and translational suppression. Biochim Biophys Acta 1779: 668-677, 2008.

22. Dillhoff M, Wojcik SE and Bloomston M: MicroRNAs in solid tumors. J Surg Res 154: 349-354, 2009.

23. Vychytilova-Faltejskova P and Slaby O: Circulating blood-borne microRNAs as biomarkers in solid tumors. Exp Suppl 106: 75-122, 2015.

24. Siegel R, Naishadham D and Jemal A: Cancer statistics, 2013. CA Cancer J Clin 63: 11-30, 2013.

25. Martinez P, Martinez-Marti A, Navarro A, Cedres S and Felip E: Molecular targeted therapy for early-stage non-small-cell lung cancer: Will it increase the cure rate? Lung cancer 84: 97-100, 2014.

26. Bhaumik D, Scott GK, Schokrpur S, Patil CK, Campisi J and Benz CC: Expression of microRNA-146 suppresses NF-kappaB activity with reduction of metastatic potential in breast cancer cells. Oncogene 27: 5643-5647, 2008.

27. Zavala V, Perez-Moreno E, Tapia T, Camus M and Carvallo P: miR-146a and miR-638 in BRCA1-deficient triple negative breast cancer tumors, as potential biomarkers for improved overall survival. Cancer Biomark 16: 99-107, 2016.

28. Tomokuni A, Eguchi H, Tomimaru Y, Wada H, Kawamoto K, Kobayashi S, Marubashi S, Tanemura M, Nagano H, Mori M and Doki Y: miR-146a suppresses the sensitivity to interferon-alpha in hepatocellular carcinoma cells. Biochem Biophys Res Commun 414: 675-680, 2011. 
29. Kao YY, Tu HF, Kao SY, Chang KW and Lin SC: The increase of oncogenic miRNA expression in tongue carcinogenesis of a mouse model. Oral Oncol 51: 1103-1112, 2015.

30. Liu R, Yi B, Wei S, Yang WH, Hart KM, Chauhan P, Zhang W, Mao X, Liu X, Liu CG and Wang L: FOXP3-miR-146-NF-кB axis and therapy for precancerous lesions in prostate. Cancer Res 75: 1714-1724, 2015.

31. Xiang $\mathrm{W}, \mathrm{Wu} X$, Huang $\mathrm{C}$, Wang M, Zhao X, Luo G, Li Y, Jiang G, Xiao X and Zeng F: PTTG1 regulated by miR-146a-3p promotes bladder cancer migration, invasion, metastasis and growth. Oncotarget 8: 664-678, 2017.

32. Ma W, Zhao X, Liang L, Wang G, Li Y, Miao X and Zhao Y: miR-146a and miR-146b promote proliferation, migration and invasion of follicular thyroid carcinoma via inhibition of ST8SIA4. Oncotarget 8: 28028-28041, 2017.

33. Zhang X, Li D, Li M, Ye M, Ding L, Cai H, Fu D and Lv Z: MicroRNA-146a targets PRKCE to modulate papillary thyroid tumor development. Int J Cancer 134: 257-267, 2014.

34. Hung PS, Liu CJ, Chou CS, Kao SY, Yang CC, Chang KW, Chiu TH and Lin SC: miR-146a enhances the oncogenicity of oral carcinoma by concomitant targeting of the IRAK1, TRAF6 and NUMB genes. PLoS One 8: e79926, 2013.

35. Saba R, Sorensen DL and Booth SA: MicroRNA-146a: A dominant, negative regulator of the innate immune response. Front Immunol 5: 578, 2014.

36. Wang RJ, Zheng YH, Wang P and Zhang JZ: Serum miR-125a-5p, miR-145 and miR-146a as diagnostic biomarkers in non-small cell lung cancer. Int J Clin Exp Pathol 8: 765-771, 2015.

37. Chen G, Umelo IA, Lv S, Teugels E, Fostier K, Kronenberger P, Dewaele A, Sadones J, Geers C and De Greve J: miR-146a inhibits cell growth, cell migration and induces apoptosis in non-small cell lung cancer cells. PLoS One 8: e60317, 2013.

38. Wang WM and Liu JC: Effect and molecular mechanism of mir-146a on proliferation of lung cancer cells by targeting and regulating MIF gene. Asian Pac J Trop Med 9: 806-811, 2016.

39. Thomson DW, Bracken CP and Goodall GJ: Experimental strategies for microRNA target identification. Nucleic Acids Res 39: 6845-6853, 2011.
40. Li Y, Vandenboom TG II, Wang Z, Kong D, Ali S, Philip PA and Sarkar FH: miR-146a suppresses invasion of pancreatic cancer cells. Cancer Res 70: 1486-1495, 2010.

41. Garcia AI,Buisson M,Bertrand P,Rimokh R, Rouleau E,Lopez BS, Lidereau R, Mikaelian I and Mazoyer S: Down-regulation of BRCA1 expression by miR-146a and miR-146b-5p in triple negative sporadic breast cancers. EMBO Mol Med 3: 279-290, 2011.

42. Forloni M, Dogra SK, Dong Y, Conte D Jr., Ou J, Zhu LJ, Deng A, Mahalingam M, Green MR and Wajapeyee N: miR-146a promotes the initiation and progression of melanoma by activating Notch signaling. Elife 3: e01460, 2014.

43. Cornett AL and Lutz CS: Regulation of COX-2 expression by miR-146a in lung cancer cells. RNA 20: 1419-1430, 2014.

44. Taganov KD, Boldin MP, Chang KJ and Baltimore D: NF-kappaB-dependent induction of microRNA miR-146, an inhibitor targeted to signaling proteins of innate immune responses. Proc Natl Acad Sci USA 103: 12481-12486, 2006.

45. Labbaye $\mathrm{C}$ and Testa U: The emerging role of MIR-146A in the control of hematopoiesis, immune function and cancer. J Hematol Oncol 5: 13, 2012.

46. Park H, Huang X, Lu C, Cairo MS and Zhou X: MicroRNA-146a and microRNA-146b regulate human dendritic cell apoptosis and cytokine production by targeting TRAF6 and IRAK1 proteins. J Biol Chem 290: 2831-2841, 2015.

47. Yousefzadeh N, Alipour MR and Soufi FG: Deregulation of $\mathrm{NF}-\kappa \mathrm{B}-\mathrm{miR}-146$ a negative feedback loop may be involved in the pathogenesis of diabetic neuropathy. J Physiol Biochem 71: $51-58,2015$

This work is licensed under a Creative Commons Attribution-NonCommercial-NoDerivatives 4.0 International (CC BY-NC-ND 4.0) License. 